\title{
Internet of Things: A Survey
}

\author{
Belkız Torğul ${ }^{1}{ }^{1}$, Lütfü Şağbanşua ${ }^{1}$, Figen Balo ${ }^{1}$
}

\section{Accepted $3^{\text {rd }}$ September 2016}

\begin{abstract}
Internet of Things (IoT) is a global infrastructure worldwide which links objects and enables data generation and sharing of this data. IoT is considered as one of the most important areas of future technology and gets attention considerably by researchers and practitioners in recent years. Applications presented by IoT makes possible a large number of developments, but very few can be used currently. With rapid advances in this system technology, successful implementations will continue to emerge to improve the quality of life in many areas. In this study, IoT is examined in general terms and its applications, advantages and disadvantages are reviewed.
\end{abstract}

\section{Keywords: Internet of Things, RFID (radio frequency identification), Sensor, Smart objects.}

\section{Introduction}

Internet has made a significant impact on the economy and society bringing exceptional network infrastructure and communication. It has been more persistent with the advent of the low cost wireless connection. With emerging technologies, billions of people are connected to the Internet via portable computers or mobile devices. After this stage, the expected big step is that interconnected computers exchange information with interconnected objects.

IoT is considered as a part of the Internet of the future and will comprise billions of intelligent communicating 'things'. You can think of all the things/objects as from cars to books, from electrical appliances to foods, from refrigerators to water heaters, from intelligent buildings to shoes that are connected with each other will be a development waiting for us in the future. Products previously consisting of only mechanical and electrical components will return to hardware, sensors, electronics and complex devices which are interconnected in a variety of formats via the internet and even some platforms [1 - 4].

It is becoming more apparent, we stand on the threshold of new computer applications era that will radically affect our lives. But the oncoming wave of technological revolution will affect us more from all directions; it seems that our near future will be filled with small processors which communicate with each other simultaneously and these will be integrated into the majority of everyday objects when their small sizes and low costs are considered [5].

Internet of Things has emerged as new platforms in the Information and Communication Technologies revolution of the 21 st century. This platform is used to provide (on demand) services and resources in different domains including education, commerce, healthcare, public sector and various governmental organizations [6]. Internet of things is a new world for connecting every object of the real world with the virtual space in the computer world. IoT is a type of network that links physical objects that surround us with the virtual world to perform information exchange [7].

When the literature is viewed, many of identification of internet of thing are seen;

${ }^{1}$ Industrial Engineering Department, Engineering Faculty, Firat University, Campus, 23279, Elazığ/Turkey

* Corresponding Author: Email: belkistorgul@gmail.com

Note: This paper has been presented at the $3^{\text {rd }}$ International Conference on Advanced Technology \& Sciences (ICAT'16) held in Konya (Turkey), September 01-03, 2016.
The Internet of Things is the connection - via the internet - of objects from the physical world that are equipped with sensors, actuators and communication technology [8].

The Internet of Things is a novel paradigm that is rapidly gaining ground in the scenario of modern wireless telecommunications. The basic idea of this concept is the pervasive presence around us of a variety of things or objects - such as Radio-Frequency Identification tags, sensors, actuators, mobile phones, etc. which, through unique addressing schemes, are able to interact with each other and cooperate with their neighbours to reach common goals [9].

The Internet of things is a things connected network, where things are wirelessly connected via smart sensors; IoT is able to interact without human intervention [4].

The internet of things is a network of objects equipped with radio frequency identification chips and similar technologies so that the objects could communicate and interact with each other [10].

The internet of things is a common worldwide network which in a unique way addressable things / objects created by them and the objects in the network are in contact each other with a specific protocol [2].

The impact of the IoT has influence on many areas in a short time. Especially, ability of IoT which adapts to any environment, in any conditions without restriction of place, time and object has made it popular [11]. IoT is currently going through a phase of rapid growth. Gartner, Inc. forecasts that 6.4 billion connected things will be in use worldwide in 2016, 30 percent more from 2015 , and will reach 20.8 billion by 2020 . In 2016, 5.5 million new things will get connected every day. Gartner estimates that the Internet of Things will support total services spending of \$235 billion in 2016, 22 percent more from 2015. Services are dominated by the professional category (in which businesses contract with external providers in order to design, install and operate IoT systems), however connectivity services (through communications service providers) and consumer services will grow at a faster pace [12]. The evolvement of IoT can be illustrated by several phases as shown in Fig. 1 [4].

In 1991, academics at the University of Cambridge share the one coffeepot where they work. Researchers whose offices on the lower floors of the building become uncomfortable to find the coffeepot empty and they design a system which captures three images of coffeepot in a minute and transfer to their computer. After writing of protocols, image capture software and with a video camera, each researcher could see the quantity of coffee in the coffee pot on the screen in real time and online. By 1993, this 
application moved web has been watched millions of times a day and it was terminated due to department move to another building in 2001. This coffee pot was the first proof and example of the existence of "Internet of Things"[2].

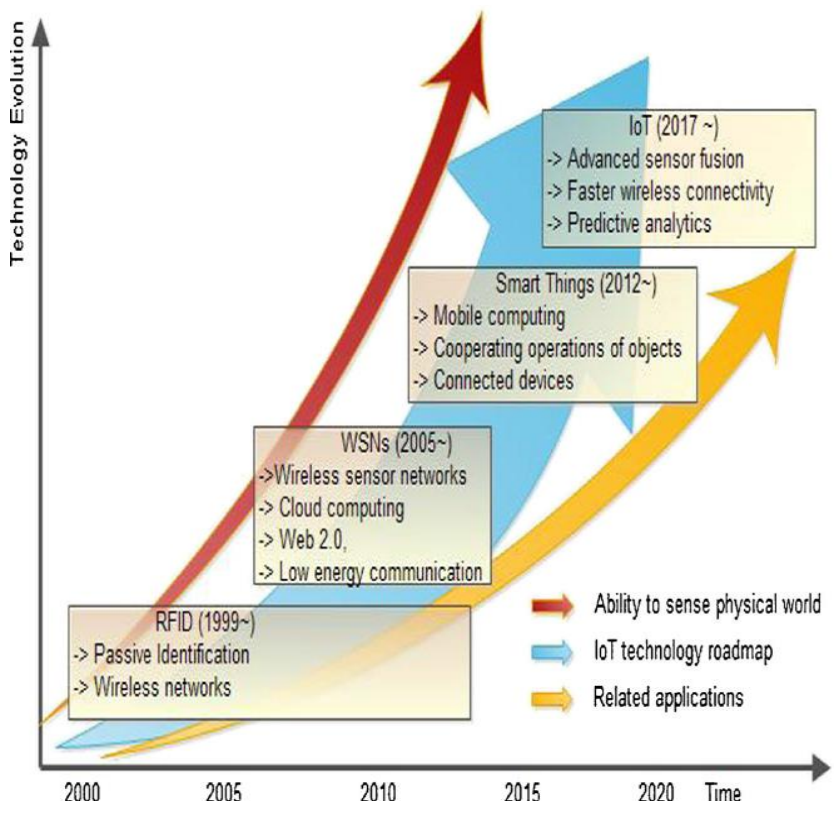

Figure 1. Evolution of the IoT [4].

The term Internet of Things was firstly coined by Kevin Ashton in 1999 in a presentation prepared for Procter \& Gamble Company. He sorted and proposed the benefits of application of RFID technology in the supply chain and the concept became popular through the Auto-ID Centre at MIT [13 - 15]. Then, scientists and researchers have gradually accepted the concept of IoT. The formal IoT concept was given by International Telecommunications Union (ITU) in 2005 ITU released the report on the Internet, titled "The Internet of Things". The academic milestones in the brief history of IoT are illustrated in Fig. $2[10,16]$

Atzori et al. [9] reported different visions of Internet of Things paradigm and surveyed the most important aspects of the IoT. Kiritsis [17] studied on intelligent products in the era of IoT.

$\mathrm{Gu}$ and Liu adapted Internet of Things applications to information management in the reverse logistics in 2013. Ondemir and Gupta proposed a mixed integer programming model used IoT for minimizing remanufacturing, disassembly, recycling, disposal and storage plans in a demand driven environment in 2014 [13].

Tsai et al. [18] reviewed studies on basic concepts, architectures, discussions and comparisons of IoT and Future Internet of Things
(FIoT) and gived open issues and challenges of IoT and FIoT. Then they presented an intelligent data management framework for the FIoT. Also similar review studies are found in $[1,4,10$, $15,19,20]$. Lee and Lee [21] presented essential IoT technologies and identified three categories of IoT applications (monitoring and control, big data and business analytics, information sharing and collaboration). They also presented investment opportunities and evaluation and discussed challenges of IoT. Shrouf and Miragliotta [22] presented a framework for IoT-based energy management to support the integration of gathered energy data into a company's information technology platforms and contributed to the understanding of energyefficient production management practices that are enhanced by the Internet of Things technology.

Dijkman et al. [8] presented a business model framework for Internet of Things applications. Sicari et al. [23] presented the main research challenges and the existing solutions in the field of IoT security. Tao et al. [16] introduced the concept, characteristics, applications of IoT and analyzed energy consumption in product life cycle. Then they summarized the existing applications of IoT in product life-cycle energy management and analyzed the potential applications and challenges of IoT in product life-cycle energy management. Verdouw et al. [24] analyzed concept of virtual food supply chains with Internet of Things and proposed an architecture to implement enabling information systems. Then they verified the proposed architecture with a case study of a fish supply chain. Fang et al. [25] presented an integrated three-stage model based on IoT technology for the optimization of procurement, production and product recovery, pricing and strategy of return acquisition and proposed a novel particle swarm optimization algorithm based on two heuristic methods to solve the problem.

Aktaş et al. [3] suggested a system based IOT which allows viewing physiological data received from hospitalized babies in infant intensive care unit targeted realization within the scope of this technology both from the hospital environment and outside the hospital environment, referring to the IoT technology applications in the health field.

The aim of this study is to examine the concept of "Internet of Things" widely used in recent years and to determine the existing situation of IoT. Thus, it was strived to obtain more information about IoT that is a technology revolution. Following the introduction, the main components of IoT described in second section and current applications of IoT were discussed in the third section. Then the potential difficulties beside the opportunities of IoT were mentioned in the fourth section. And study is terminated with conclusion section.

\section{Functional View of IoT}

Internet of Things is comprised of three main components. These are;

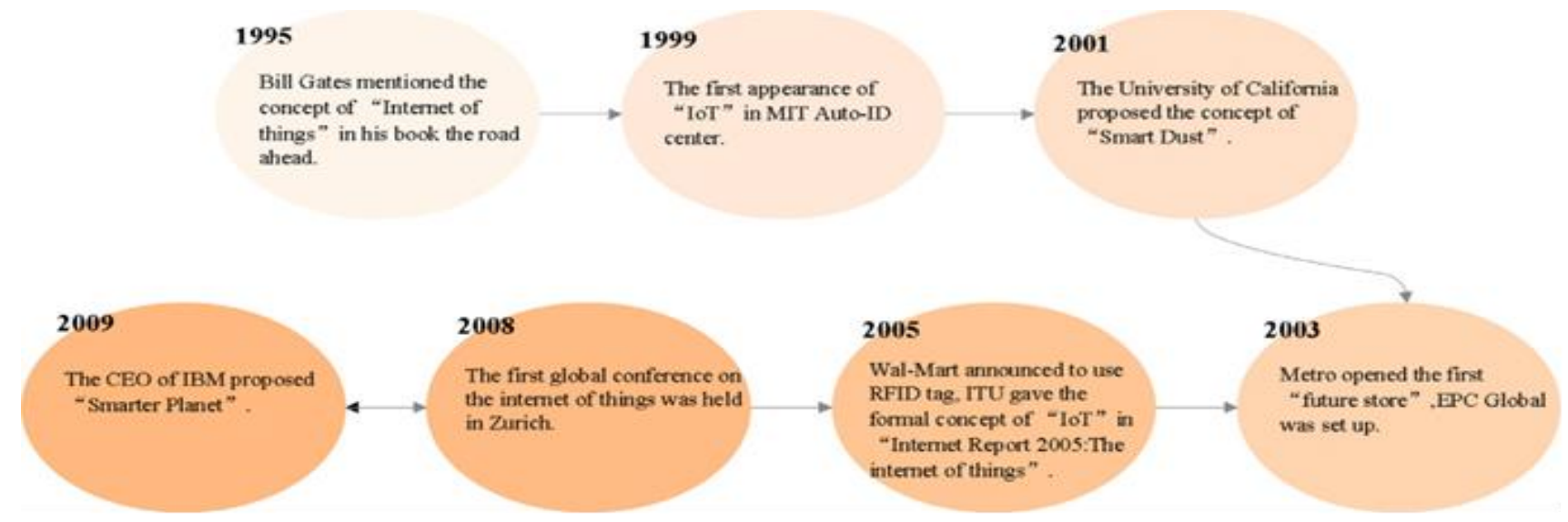

Figure 2. Brief history of IoT [16]. 
1. Assets that represent portion of "Objects" of Internet of Things concept,

2. Networks that link these objects,

3. Computer systems that use data from the object [26].

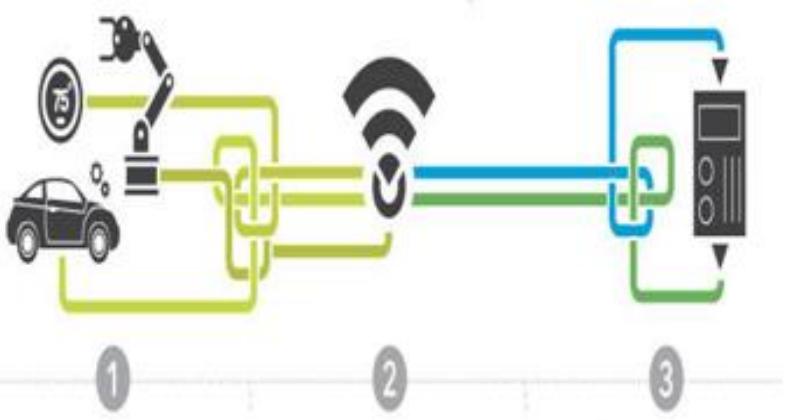

Figure 3. Three main components of Internet of Things [26].

Internet of Things is an interplay of smart objects and smart communication networks and include own system storage, computing, visualization and interpretation tools for data analytics $[15,22]$.

When objects equipped with sensors and electronic circuits, they begin to acquire properties "thinking", "feeling" and "speaking". Thus, they have access the ability to update their own status information by contacting us [2].

Smart objects embedded device of IoT;

1. It has a unique identity.

2. It has the ability to communicate effectively with environment.

3. It has obtained and storage capability data related itself.

4. It deploys a language to show properties, production demands etc.

5. It has capable of making decisions about its own fate [27].

They can communicate and interact either among themselves, building networks of interconnected objects, or with end-users or other entities in the network [20].

Think of a cup that can access the Internet. It is able to detect what is the liquid put into it. Not only as a species; also in terms of the content-forming composition. This information can be transferred to a desired application or environment on the internet. Thus, you can examine the knowledge of fluid you drink throughout the day, for example through an application on your smart phone, at the end of the day. Cups, on top of that, can keep statistics. It can map your liquid consumption by determining what you drank in what time of day. It can suggest that you drink coffee when your coffee time. Even it can order instead of you at a nearby coffee shop [28].

Actualization of IoT into the real world is possible by the integration of several effective technologies [9]. These technologies are provided below.

\subsection{Radio Frequency Identification (RFID)}

Radio frequency identification allows automatic identification and data capture using radio waves, a tag and reader. RFID is key component of IoT system and also the newest identification technique among all IoT technologies. RFID as a technology for IoT is used to identify and track items. If objects (even people or animals) are equipped by identifiers, they can be managed and registered automatically; therefore, it is then possible to track the full transportation way of these objects $[9,14,21]$.

Passive RFID are not battery-powered, therefore they use the power of the reader's interrogation signal to communicate. Active RFID tags contain sensors and have their own battery supply and can communicate. Although passive RFID tags are sufficient for tracking, active RFID tags with embedded sensors can provide a lot more information about the usage/condition of objects. Sensor detects the changes in the value of various measures such as temperature, pressure, vibration and humidity and converts the signal to be recorded. RFID tag containing static information such as serial number, model, bill of materials, production and delivery date of the product is connected to the product and can be updated after the operations such as each maintenance, improvement. Dynamic information such as environmental conditions occurring during use of the product, working time and frequency of the product is recorded with the help of sensors [13, 15, 21]. Fig. 4 shows building blocks of IoT.

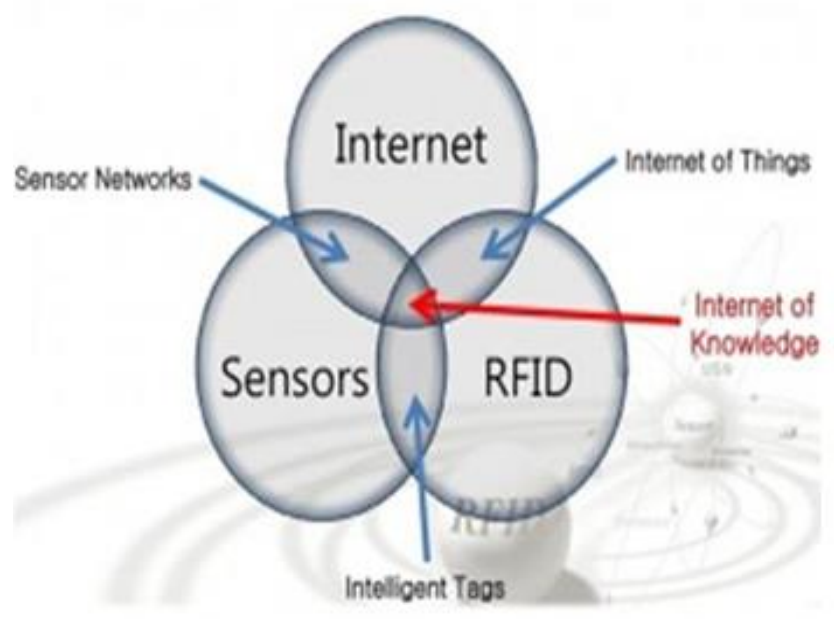

Figure 4. Internet of Things [29]

\subsection{Wireless Sensor Networks (WSN)}

Wireless network which contains vehicles working independently and use sensors to monitor a cooperative manner physical or environmental conditions such as temperature, humidity, light, sound, pressure, pollution, soil composition, noise level, vibration, object moves in different places is called "wireless sensor network". Sensor networks play a crucial role in the IoT. Typical Wireless Sensor Networks consist of hundreds or even thousands of sensor nodes that connect via a wireless environment and exchange information with each other. Improvements in hardware and wireless system have enabled the production of low cost, low power consumption, multifunctional miniature sensing devices. Ad hoc networks can be created with the help of hundreds-thousands of these devices. For example, these devices create a wireless ad hoc network distributing over a wide geography. These sensors that distributed and formed the network generate a sensing network system by cooperating. A sensor network allows to access information easily at anytime, anywhere. It performs this function by collecting, processing, analysing and spreading data. [30].

The integration of WSN and RFID empowers IoT and makes possible to develop IoT applications [4].

\subsection{Middleware}

Middleware is a software layer between the technological and the application levels. Middleware architectures proposed in the last years for the IoT [9]. The complex distributed platform of the IoT requires simplifying the development of new applications and services, so use of middleware is an ideal option with IoT application development. More importantly, a centralized infrastructure to support storage and analytics is required. Storage and calculating tools for data analytics are included in 
middleware. The data have to be stored and used intelligently for smart monitoring and actuation. Many IoT applications require massive data storage, huge processing speed to enable real time decision making, and high-speed broadband networks to stream data. As of 2012, Cloud based storage solutions are becoming increasingly popular. Cloud computing provides an ideal backend solution for handling huge data streams and processing them for the numerous number of IoT devices and humans in real time $[1,15,21]$.

\subsection{Presentation}

Presentation is related to visualization and interpretation tools. These tools can be accessed on any platform and can be designed for a large variety of applications. Presentation allowed the interaction of the user with the object in real time anywhere, anytime is important for IoT systems [1, 15]. For example, IoTenabled home appliances and devices can be monitored and controlled outside the user's home through a computer, tablet, or smart phone due to presentations function of IoT [21].

\section{Applications of IoT}

Internet of Things that is called a new industrial revolution in the whole world finds itself in many fields of application possibilities. In recent years, it has attracted great attention and is used in various fields by researchers and practitioners worldwide. Opportunities offered by the IoT make possible the development of a large number of applications [9]. IoT have been widely used in Transportation, Smart Home, Smart Factory, Smart City, Supply chain, Lifestyle Security, Retail, Agriculture, Emergency, Health care, Culture and tourism, User interaction, Environment and Energy, Library services, Food and restaurant industry and many other areas (Fig. 5). In the following subsections, a few typical applications examples are given.

\subsection{Smart Environments}

A smart environment can be an office, home, industrial plant, city or any environment and it make our life more comfortable due to the intelligence of included objects [9].

Home appliances such as televisions, washing machines, refrigerators, air conditioners and many other devices can be controlled very efficiently, so, this smart system provide better home and energy management [1].

For example, rooms heating can be adjusted to our preferences and to the weather; lighting can change according to the time of the day; dangerous incidents can be prevented with suitable monitoring and alarm systems; and energy can be saved by automatically switching off the electrical equipments when not needed [9]. For communication between people and the smart environment a smart phone can be used. So far, there are several applications available for Apple iOS, Google Android and Windows Phone operating systems that measure various parameters [15].

\subsection{Transportation and Logistics}

IoT really plays an increasingly important role in transportation and logistics. Intelligent transport systems that count vehicles on the road, calculate the travel time, determine the pits and calculate the using time of the parking place can be established with the help of sensors. Moreover, it is possible to realize better traffic management with data obtained from such a system [31]. Internet of Things means that the rich data and deep intelligence for all parties in the network from the manufacturer to the end user for supply chain.

Real-time monitoring and object move tracking from an origin to a destination will be guaranteed with objects attached RFID tags or sensors so that transportation and logistics can be more efficient and accurate during the entire supply chain [16].

Some important benefits of internet of things related to the supply chain;

- The storage can be monitored in real time. Both the number of stored product and the costs can be reduced by eliminating

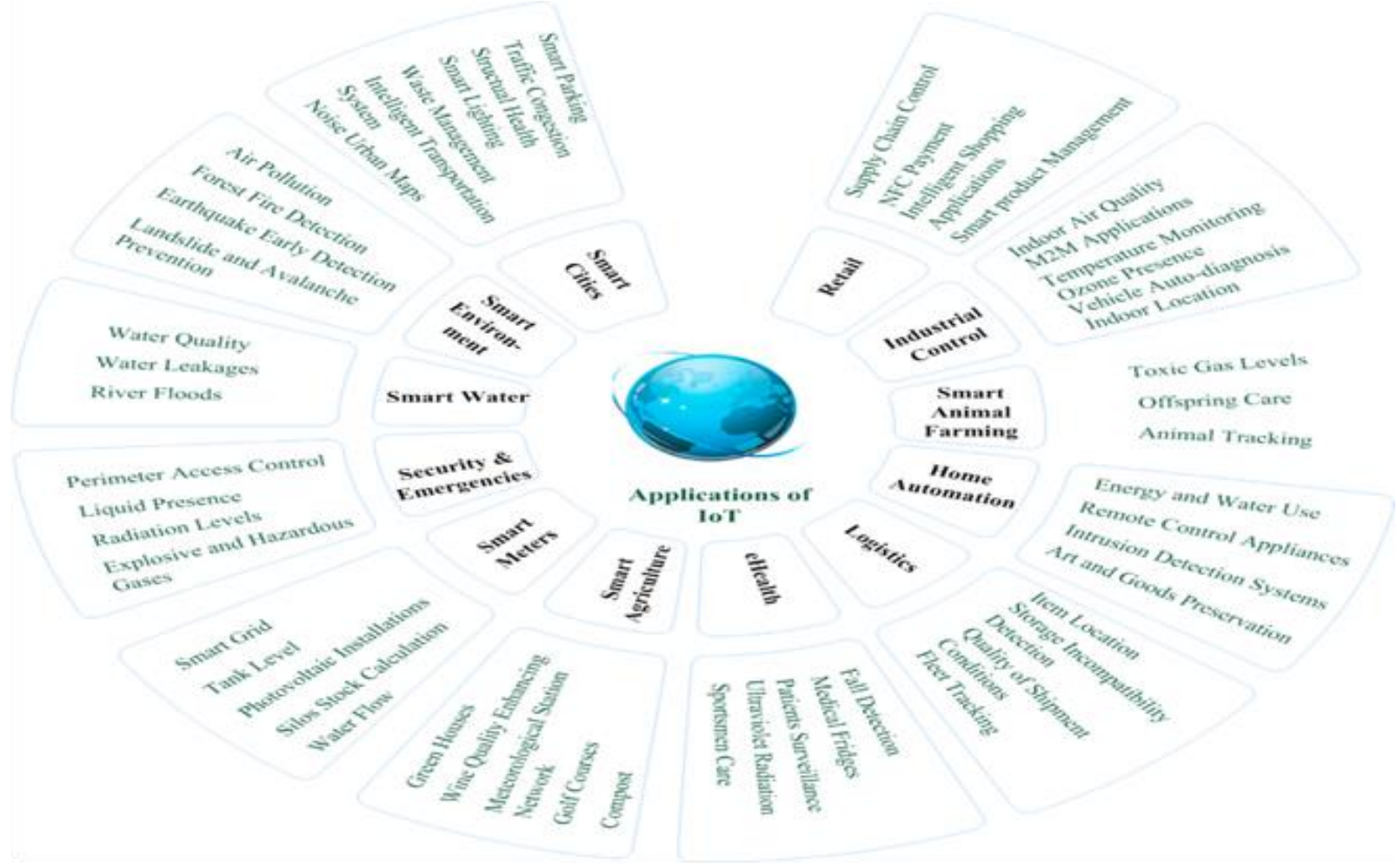

Figure 5. Applications of IoT. 
redundant production and storage. In addition, turnaround time can be shortened; needless handling, loss and theft can be prevented.

- Prevents alteration of information enabling to store all kinds of information (Eg. Production date, expiry date, warranty period, after sales details) in objects and share by supply chain stakeholders in real-time.

- Business process optimization; smart objects used in the framework of business processes accelerate and facilitate the detection of potential problems and support the detection of a possible process optimization [32].

\subsection{Health Care}

Healthcare is an important application area of IoT and in this sector, a number of applications containing IoT technologies can be found. Internet of Things offers a variety of solutions at the stage of take measures, monitories and diagnose depending on the health status. Devices can help individuals to control their own health status such as weight, body mass, sleep patterns and daily activity rate [31].

This systems include identification for reduce incidents harmful to patients such as wrong drug/dose/time/procedure. Tracking for identify of a person or object in motion. Data collection and transfer for reducing form processing time and medical inventory management. Sensing for diagnose patient conditions [9].

Patients carry medical sensors to monitor parameters such as body temperature, blood pressure, breathing activity. All the healthcare-related information is collected by these sensors and managed efficiently and it can be able to perform advanced remote monitoring and can be capable of rapid response actions when needed. For example, fall detection application can help elderly or disabled people live more independently $[16,20]$. It can be foreseen that the IoT with intelligent medical sensors will enhance the quality of life significantly and prevent the occurrence of health problems.

On the other hand, the rapid development of mobile devices and health applications creates a huge market for the application of IoT. Individual mobile health applications have been developed to serve healthcare tasks such as the measurement of blood pressure or recording of blood glucose [4].

\subsection{Security and Emergency}

Internet of Things can enhance security and help government in the emergencies. Devices that transfer information between each other quickly can be built in a condition of natural disasters or requires medical priority. Apart from that, ambient sensors can be used to monitor the presence of dangerous chemicals. Sensors monitoring the behaviour of people can be used to assess the presence of people acting in a suspicious way [20].

\subsection{Agriculture}

Internet of Things allows to establishment of smart fields that each step can be observed to increase agricultural production. The atmospheric, water, soil, and other information can be collected in real time and accurately with IoT technology to improve the efficiency and quality of agricultural production [16]. The smart irrigation systems provide ease about giving information about the condition of the soil and reducing water consumption with the aid of sensors. The system analyzes the data collected and realizes the irrigation process according to soil needs in the area where the irrigation system is installed. In addition, solutions based data offered by the Internet of things offers the option to be able to follow even the food which they eat to consumers in terms of food security [31].
Apart from these applications, many others may be envisaged many other applications that are define futuristic, because these base on some technologies that either is still coming or whose practice is still too complex [9].

\section{Pros and Cons of IoT}

Internet of things feed on data in the continuous flow and composed of a variety of devices and millions of sensors is a technology that enables to facilitate our lives with many uses area and develop business processes. Data usability, continuous monitoring capability, time (money) savings are among the main advantages of the system. But, there are also challenges alongside opportunities that this system offers us. Although the success of IoT has confirmed the potentials, we have to confront with the challenges of IoT soon [18]. The disadvantages that are believed to be slowly eliminated result of the adoption of this technology;

\subsection{Complexity}

IoT is a very complex heterogeneous network included the connections among different networks through several communication technologies [4]. Data collected from sensors of IoT will become very large because of enormous amount of things connected internet. Current computer systems or sensors may not have enough storage to keep all this data [18]. The amount of data that will be occurred by billions of objects connected to this system will increase incredibly and this large data processing will become difficult and complex task.

\subsection{Security and Privacy}

The system establishes on a huge of network system bring along the cyber security risks. Main security issues in IoT are illustrated in Fig. 6.

IoT will gather and store huge amount of personal information due to increase in connected devices. And so, this data is attractive to hackers and other cyber criminals [1]. There are many ways IoT system could be attacked disabling the network availability; pushing erroneous data into the network; accessing personal information; etc. [15].

Although a number of projects have been developed for security and privacy protection, a reliable security protection mechanism for IoT is still in demand for data confidentiality, privacy, and trust [4]. This is the most important issue to prevent the use and become widespread of IoT. Therefore, valid security, privacy and trust models suitable for the IoT applications should be define and sensible solutions (such as intrusion prevention systems, firewalls) should be found in terms of technical to ensure customer privacy and security because, the run-up and acceptance of IOT technology will depend on the protection of users' privacy. 


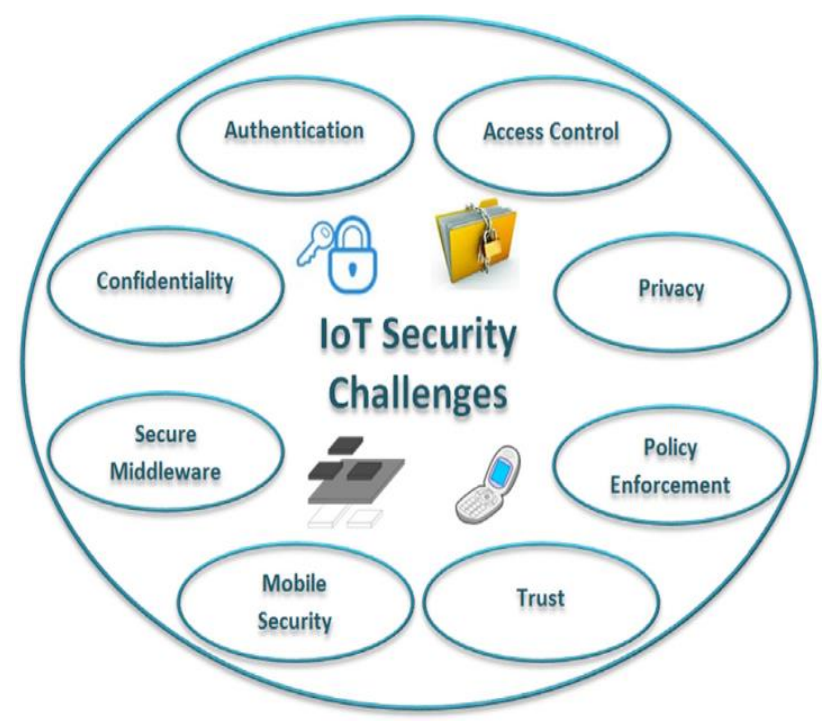

Figure 6. Security Challenges of IoT [23].

\subsection{Convenience}

Another concern for the Internet of Things is the problem of convenience. Since currently Internet of things is the initial phase of the idea and development, there are yet no convenience standards for labeling, monitoring equipment, providing data definition, capture and exchange, special software, end to end security and individual management etc. $[10,26,33]$. In recent years, a number of standardization activities focused tag-based technologies have been active and these standardization activities on the sensor and RFID [20].

\section{Conclusion}

Internet, indispensable of today, is highly effective in many areas such as education, business life, communication and daily life. But, traditional internet is not sufficient in capturing real-time data because it still depends on people. Internet of things is a technology that objects and creatures can transfer data connected to Internet without need for human-human and human-computer interaction [34]. Therefore, IoT is considered as part of the overall Internet of the future, which is likely to be dramatically different from the Internet we use today [9]. Given that humans advance and evolve by turning data into information, knowledge, and wisdom, IoT plays a very important role in the future emerging technology and it has the potential to change the world as we know it today for the better [1, 10].

If IoT that provides connection of any object, anyone, anytime and anywhere correctly applied, increase of things/ objects that produce their data by themselves in real time will bring more reliable knowledge. Thus, the losses will be reduced, the waste will be prevented and after that costs will decrease. But unless required standards and rules of this system, the situations be encountered may blow innovativeness. For this, like all technological viewpoint innovations, the changes should be expected and accepted.

In conclusion, IoT represents the next evolution of the Internet and for a few years now, IoT has been developed dramatically and a great number of enabling technologies have been proposed. In this paper, some studies conducted up to this day were summarized mentioning the development of internet of things. Later, the main components of IoT described and current applications of IoT were given. Finally, the potential difficulties beside the opportunities of IoT were mentioned. It is expected that this survey will be useful for researchers and practitioners, helping them to understand enormous potential of Internet of Things and in addition this, to foresee the challenges of IoT which will be encountered.

\section{References}

[1] Chandrakanth, S., Venkatesh, K., Uma Mahesh, J. and Naganjaneyulu, K. V. Internet of Things. International Journal of Innovations \& Advancement in Computer Science, Vol. 3, Iss. 8, 2014, pp. 16-20.

[2] Kutup, N. Nesnelerin Interneti; $4 \mathrm{H}$ Her yerden, Herkesle, Her zaman, Her nesne ile bağlant1. 16. Türkiye'de İnternet Konferans1 inet-tr'11, 2011.

[3] Aktaş, F., Çeken, C. and Erdemli, Y. E. Nesnelerin İnterneti Teknolojisinin Biyomedikal Alanındaki Uygulamaları. Düzce Üniversitesi Bilim ve Teknoloji Dergisi, Vol. 4, Iss. 1, 2016, pp. 37-54.

[4] Li, S., Da Xu, L. and Zhao, S. The internet of things: a survey. Information Systems Frontiers, Vol. 17, Iss. 2, 2015, pp. 243-259.

[5] Yiğitbaşi, Z. H. Nesnelerin İnterneti ve Makineden Makineye Kavramlari İçin Kilit Öncül-IPv6.

[6] Younas, M., Awan, I. and Pescape, A. Internet of Things and Cloud Services. Future Generation Computer Systems, Vol. 56(C), 2016, pp. 605-606.

[7] Erguler, I. A potential weakness in RFID-based Internet-ofthings systems, Pervasive and Mobile Computing, Vol.20, 2015, pp. 115-126.

[8] Dijkman, R. M., Sprenkels, B., Peetersa, T. and Janssen, A. Business models for the Internet of Things, International Journal of Information Management, Vol. 35, Iss. 6 , 2015, pp. 672-678.

[9] Atzori, L., Iera, A. and Morabito, G. The internet of things: A survey, Computer networks, Vol. 54, Iss. 15, 2010, pp. 2787-2805.

[10] Machado, H. and Shah, K. Internet of Things (IoT) impacts on Supply Chain, [online], Available: http://apicsterragrande.org/images/articles/Machado__Inter net_of_Things_impacts_on_Supply_Chain_Shah_Machado _Second_Place_Grad.pdf/

[11] Çeltek, S. A., Soy, H. and Hacıbeyoğlu, M. Nesnelerin İnternetine Doğru: Güncel Konular ve Gelecekteki Eğilimler.

[12] "Gartner Says 6.4 Billion Connected "Things" Will Be in Use in 2016, Up 30 Percent From 2015," Analysts to Explore the Value and Impact of IoT on Business at Gartner Symposium/ITxpo, Nov. 8-12, 2015. Available: http://www.gartner.com/newsroom/id/3165317

[13] Paksoy, T., Karaoğlan, İ., Gökçen, H., Pardalos, P. M. and Torğul, B. An Experimental Research on Closed Loop Supply Chain Management with Internet of Things, Journal of Economics Bibliography, Vol. 3(1S), 2016, pp. 1-20.

[14] Kadlec, J., Kuchta, R. and Novotný, R. RFID Modular system for the Internet of Things (IoT). Industrial Engineering \& Management, vol. 3(4), 2014.

[15] Gubbi, J., Buyya, R., Marusic, S. and Palaniswami, M. Internet of Things (IoT): A vision, architectural elements, and future directions. Future Generation Computer Systems, Vol. 29, Iss. 7, 2013, pp. 1645-1660.

[16] Tao, F., Wang, Y., Zuo, Y., Yang, H. and Zhang, M. Internet of Things in product life-cycle energy management. Journal of Industrial Information Integration, 
Vol. 1, 2016, pp. 26-39.

[17] Dimitris, K. Closed-loop PLM for intelligent products in the era of the Internet of things, Computer-Aided Design, Vol. 43, Iss. 5, 2011, pp. 479-501.

[18] Tsai, C. W., Lai, C. F. and Vasilakos, A. V. Future Internet of Things: open issues and challenges. Wireless Networks, Vol. 20, Iss. 8, 2014, pp. 2201-2217.

[19] Wortmann, F. and Flüchter, K. Internet of Things, Bus Inf Syst Eng, Vol. 57, Iss. 3, 2015, pp. 221-224.

[20] Miorandi, D., Sicari, S., De Pellegrini, F. and Chlamtac, I. Internet of things: Vision, applications and research challenges. Ad Hoc Networks, Vol. 10, Iss. 7, 2012, pp. 1497-1516.

[21] Lee, I. and Lee, K. The Internet of Things (IoT): Applications, investments, and challenges for enterprises, Business Horizons, Vol. 58, Iss. 4, 2015, pp. 431-440.

[22] Shrouf, F. and Miragliotta, G. Energy management based on Internet of Things: practices and framework for adoption in production management, Journal of Cleaner Production, Vol. 100, 2015, pp. 235-246.

[23] Sicari, S., Rizzardi, A., Grieco, L. A. and Coen-Porisini, A. Security, privacy and trust in Internet of Things: The road ahead. Computer Networks, Vol. 76, 2015, pp. 146-164.

[24] Verdouw, C. N., Wolfert, J., Beulens, A. J. and Rialland, A. Virtualization of food supply chains with the internet of things. Journal of Food Engineering, Vol. 176, 2016, pp. 128-136.

[25] Fang, C., Liu, X., Pardalos, P. M. and Pei, J. Optimization for a three-stage production system in the Internet of Things: procurement, production and product recovery, and acquisition. The International Journal of Advanced Manufacturing Technology, Vol. 83(5-8), 2016, pp. 689710 .
[26] Y1lmaz, B. Internet of Things (IoT) Nedir? [online], Available: https://burkanylmz.wordpress.com/2015/10/12/internet-ofthings-iot-nedir/

[27] McFarlane, D., Giannikas, V., Wong, A. C. and Harrison, M. Intelligent products in the supply chain-10 years on. IFAC Proceedings Volumes, Vol. 45, Iss. 6, 2012, pp. 655660.

[28] 2016 [online], Available: https://ooofoffline.wordpress.com/tag/nesnelerin-interneti/

[29] 2016 [online], Available: http://www.smallcapnetwork.com/Small-Cap-AtmelCorporation-ATML-Has-the-Internet-of-Things-CoveredAMBA-FLEXCSCO/s/via/3414/article/view/p/mid/1/id/1803/

[30] Dolay, B. 2016 [online], Available: http://ebergi.com/y/Kablosuz-Sensor-Aglari/

[31] Atakul, B. Nesnelerin İnterneti ve Kullanım Alanları, 2015 [online], Available: http://www.teknolo.com/nesnelerininterneti-kullanim-alanlari/

[32] Bayrak Meydanoğlu, E.S. IoT ve tedarik zinciri, Lojistürk Dergisi, Vol. 34, 2013, pp. 28.

[33] He, M., Ren, C., Wang, Q., Shao, B. and Dong, J. The internet of things as an enabler to supply chain innovation. In e-Business Engineering (ICEBE), 2010 IEEE 7th International Conference on, November 2010, pp. 326-331.

[34] Ramesh A .N., Kambhampati C. J.R.T. Monson J.R.T. \& Drew P.J. Artificial intelligence in medicine, Annals of The Royal College of Surgeons of England, Vol. 86, Number 5, 2004, pp. 334-338.

[35] Köroğlu, O. Nesnelerin Interneti, algılayıcı ağları ve medya. 